\title{
Kekuatan Perlekatan Tarik Komposit Resin Pada Permukaan Enamel Dengan dan Tanpa Perlakuan Fluor
}

\author{
Edhie Arif $\mathbf{P}^{1}$, Cecilia G.J. Lunardhi ${ }^{1}$, Arif Setiawan ${ }^{2}$ \\ 1 Dosen Departemen Ilmu Konservasi Gigi \\ ${ }^{2}$ Mahasiswa PPDGS Ilmu Konservasi Gigi \\ Departemen Ilmu Konservasi Gigi \\ Fakultas Kedokteran Gigi - Universitas Airlangga \\ Surabaya - Indonesia
}

\begin{abstract}
ABSTRAK
Background: Several studies showed that treatment of fluoride in enamel has an important role in the prevention of caries in patients with a history of high risk caries. Enamel are often exposed to fluoride forms a new bond (fluoroapatite) which is stable and difficult to dissolve in acidic conditions. And it affects in the adhesion strength of a composite restorative materials. Objective: To prove the difference tensile strength attachment surface tooth enamel with fluoride treatment and no fluoride treatment. Materials and Methods: 14 samples of bovine teeth were divided into two groups, each group consisting of 7 samples. After preparation, sample immersed in artificial saliva with $\mathrm{pH} 4.6$ for three hours. Group I sample with fluoride treatment, group II sample without fluoride treatment, both groups then immersed in artificial saliva with $\mathrm{pH} 7$ for 14 days. Then samples were inserted into plunger and withdrawn with the autograph engine. Data were analyzed using Independent t-test ( $p$ <0.05). Results: Treatment of fluoride that generates a new bond (fluoroapatite) that is resistant to acidic conditions. This led to reducing of enamel dissolution by acid etching so that decrease the porosity ofenamel that causes the attachment strength of the composite againts enamel is reduced. Conclusions: The strength of the composite tensile adhesion to enamel with fluoride treatment is lower than the enamel without fluoride treatments.
\end{abstract}

Keywords: Enamel, fluoride, high risk caries, tensile strength, composite

Korespondensi: Arif Setiawan, Departemen Ilmu Konservasi Gigi, Fakultas Kedokteran Gigi, Universitas Airlangga, Surabaya, Indonesia.

E-mail:ariffian11@gmail.com.Telepon:+6285631024

\section{PENDAHULUAN}

Karies ini merupakan masalah kesehatan baik di negara maju maupun di negara-negara berkembang. Berdasarkan Survei Kesehatan Rumah Tangga (SKRT) pada tahun 2004, dinyatakan bahwa penyakit karies masih merupakan masalah serius terhadap kesehatan gigi dan mulut di Indonesia dengan angka prevalensi sangat tinggi yaitu $90,05 \%$. Data Departemen Kesehatan dari Riset Kesehatan Dasar tahun 2013 menunjukkan indeks DMF-T adalah 4,6 yang berarti kerusakan gigi penduduk Indonesia 460 buah gigi per seratus orang (Depkes RI, 2013).

Penyebab karies adalah bersifat multifaktorial dimana keempat kondisi penyebab terjadinya karies dapat terjadi bersamaan yaitu: bakteri kariogenik, permukaan gigi yang rentan, karbohidrat (sukrosa \& glukosa) dan waktu. Kondisi asam yang disebabkan oleh aktivitas bakteri tertentu dapat menurunkan $\mathrm{pH}$ plak dibawah 5 dalam waktu 1-3 menit dan penurunan $\mathrm{pH}$ yang berulang-ulang dalam waktu tertentu dapat 
mengakibatkan demineralisasi permukaan gigi sehingga gigi mengalami karies (Koch \& Poulson, 2001).

Banyak metode untuk mencegah maupun menghambat terjadinya resiko karies salah satunya dengan penggunaan aplikasi fluoride. Pada pasien dengan resiko tinggi karies penggunaan pasta gigi berfluoride tinggi $(5000 \mathrm{ppm})$ sehari dua kali terbukti efektif dalam menanggulangi keparahan karies (Sandra \&Amstrong, 2007). Bahan lain yang sekarang banyak dipakai untuk aplikasi topikal adalah varnis fluor $(5 \% \mathrm{NaF} \approx 22000 \mathrm{ppm} \mathrm{F})$ (Zimmer S et al., 1999). Topikal Varnis fluor yang diberikan pada pasien dengan riwayat rentan karies selama enam bulan, menunjukkan penurunan karies sebesar $37 \%$. Pemberian topikal setahun dua sampai tiga kali cukup efektif dalam pencegahan karies parah (Sandra \& Amstrong, 2007).

Pada gigi yang telah mengalami topikal aplikasi varnis fluoride untuk beberapa waktu tertentu menyebabkan

peningkatan penyerapan fluoride oleh enamel. Fluoride ini berinterakasi dengan hydroxyapatite membentuk fluoroapatite. Pada fase ini, gigi tidak akan mudah terpengaruh terhadap kondisi asam (Mc Intyre 2004; Edhie Arief \& Kunarti, 2007).

Pada beberapa studi menunjukkan adanya penurunan kekuatan perlekatan komposit ataupun resin bonding terhadap permukaan gigi yang telah mengalami topikal aplikasi fluoride ( Prawati et al., 2005; Leodido et al.; Akca, 2007).

Tujuan dari penelitian ini adalah Membuktikan perbedaan kekuatan perlekatan tarik permukaan enamel gigi dengan perlakuan fluor dan enamel gigi tanpa perlakuan fluor.

\section{BAHAN DAN METODE}

Pada penelitian ini menggunakan 14 (empat belas) gigi insisivus sapi yang diekstraksi setelah hewan tersebut dilakukan penyembelihan. Gigi incisivus yang baik dicabut dan dibersihkan dengan sikat dan scalpel tajam di bawah air mengalir (selama pembersihan gigi dalam keadaan basah), gigi yang sudah bersih direndam dalam larutan fisiologis dan disimpan dalam lemari es suhu $4^{\circ} \mathrm{C}$. Sampel gigi dipotong dalam keadaan basah dengan diamond disc dan dipisahkan bagian mahkota dan akarnya. Permukaan enamel mahkota bukal dibuat datar dengan bur intan bentuk fissure. Bubuk gips keras dicampur dengan air dan diaduk menggunakan spatula sesuai petunjuk pabrik. Cetakan silinder diolesi vaselin dan siapkan gips keras.Kemudian adonan gips keras dituangkan kedalam cetakan silinder sampai penuh, taruh gigi di tengah cetakan letakkan glass lab dan ditunggu sampai gips mengeras. Enamel dihaluskan dengan kertas gosok no.400 diteruskan dengan no.1000 (selama penghalusan dilakukan dalam keadaan basah dengan menyemprot air dari spuit injeksi 3,5 ml), Spesimen dibagi menjadi 2 kelompok : kelompok 1 sampel demgan perlakuan Fluor (Clinpro 5\% sodium Fluor) sebanyak tujuh sampel dan kelompok II Sampel tanpa perlakuan fluor sebanyak tujuh sampel. Specimen disimpan dalam saliva buatan $\mathrm{pH}$ 4,6 selama tiga jam. Kemudian sampel disimpan dalam saliva buatan $\mathrm{pH} 7$ selama 14 hari pada suhu $37^{\circ} \mathrm{C}$. Setiap 24 jam specimen kedua kelompok diganti dengan saliva buatan yang baru. Kelompok I perlakuan fluor dengan mengoleskan fluor (Clinpro 5\% $\mathrm{NaF}$ ) terhadap sampel sebelum direndam pada saliva buatan $\mathrm{pH}$ netral. Bagian enamel ditutup dengan adhesive tape yang berlubang $5 \mathrm{~mm}$ dan dilekatkan di tengah permukaan enamel. Dilakukan etsa asam fosfat $37 \%$ sebanyak 1 tetes $(0,01 \mathrm{ml})$ pada enamel selama 15 detik.

Enamel dicuci dengan air selama 15 detik kemudian dikeringkan dengan diusap cotton pellet dan semprotan angin hingga enamel betul-betul kering dan terlihat keputihan. Resin bonding diteteskan pada microbrush sebanyak 1 tetes $(0,01 \mathrm{ml})$ dan dioleskan pada 
enamel. Kemudian dilakukan penyinaran dengan light curing unit selama 20 detik ( sinar tampak dengan panjang gelombang 400-800 nm). Silinder gips dimasukkan ke dalam plunger bawah dan difiksasi dengan memasang pengunci. Pada plunger atas diisi dengan komposit dualcured (core it) sebagai bahan tumpatan di atas resin bonding. Komposit ditakar $(0,1$ gr $)$ dimasukan hingga memenuhi cawan glass.Sampel gigi yang telah diberi pembatas isolatif dengan diameter $5 \mathrm{~mm}$ dilekatkan dengan komposit dalam cawan glass, kemudian difiksasi dan dilakukan curing selama 20 detik ( curing dengan sinar tampak dengan panjang gelombang 400-800 nm). Sampel disimpan dalam suhu ruangan selama 24 jam setelah itu sampel siap dilakukan uji kekuatan tarik.

Setelahhasil data penelitian

didapatkan, kemudian dilakukan pengujian normalitas KolmogorovSmirnov untuk mengetahui distribusi populasi data setiap kelompok. Setelah mengetahui bahwa data berdistribusi normal maka dilakukan uji signifikansi perbedaan kekuatan perlekatan tarik enamel yang diberi perlakuan fluor dan enamel tanpa perlakuan fluor dengan uji Independent $t$-Test.

\section{HASIL}

Pada penelitian ini menggunakan 14 sampel penelitian yang dibagi menjadi dua kelompok. Tujuh sampel mendapatkan perlakuan menggunakan Fluor dan tujuh sampel sisanya tidak mendapatkan perlakuan Fluor. Setelah dilakukan pengukuran kekuatan perlekatan tarik, didapatkan hasil sebagai berikut, Pada penelitian ini menggunakan 14 sampel penelitian yang dibagi menjadi dua kelompok. Tujuh sampel

mendapatkan perlakuan menggunakan Fluor dan tujuh sampel sisanya tidak mendapatkan perlakuan Fluor. Setelah dilakukan pengukuran kekuatan perlekatan tarik, didapatkan hasil sebagai berikut :

\section{Rata-rata dan Standart Deviasi (SD)}

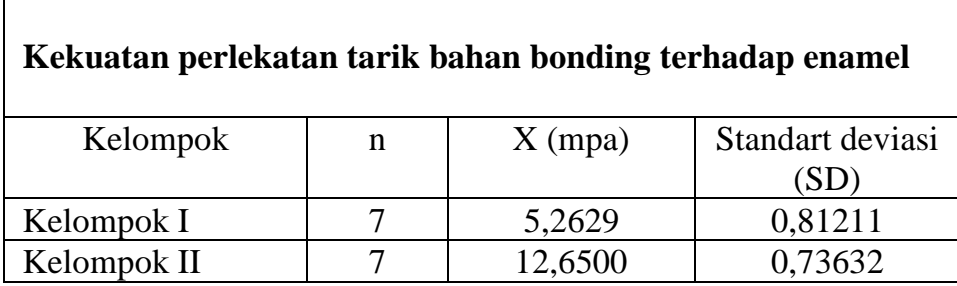

*Kelompok I : Enamel dengan perlakuan Fluor

*Kelompok II: Enamel tanpa perlakuan Fluor

Pada tabel di atas menunjukkan rata-rata kelompok sampel dengan pelakuan Fluor memiliki nilai kekuatan perlekatan tarik yang lebih rendah daripada kelompok sampel tanpa perlakuan Fluor.

Untuk mengetahui perbedaan kekuatan perlekatan tarik bahan bonding terhadap enamel antara kelompok yang mendapatkan perlakuan Fluor dan kelompok yang tidak mendapatkan Fluor dipakai uji statistik Independent t-Test. Hal ini disebabkan karena pada kelompok yang akan diuji mempunyai skala pengukuran data berbentuk rasio, terdiri dari dua kelompok, berdistribusi normal dan yang akan kita pergunakan adalah uji perbedaan.

Dari hasil analisis uji Independent $t$ - Test antara kelompok yang mendapatkan perlakuan Fluor dan kelompok yang tidak mendapatkan perlakuan Fluor didapatkan nilai $\mathrm{p}=0,00$ $(\mathrm{p}<0,05)$, hal ini menunjukkan bahwa ada perbedaan yang bermakna kekuatan perlekatan tarik bonding terhadap enamel pada kelompok sampel yang mendapatkan pelakuan Fluor dan kelompok sampel tanpa perlakuan Fluor. 


\section{DISKUSI}

Penelitian ini membandingkan kekuatan perlekatan tarik bahan bonding terhadap enamel yang mendapatkan perlakuan Fluor dan enamel yang tidak mendapatkan perlakuan Fluor. Hasil uji statistik menunjukkan bahwa kekuatan perlekatan tarik bonding terhadap enamel $(\mathrm{p}<0,05)$. Hal ini sesuai hipotesis penelitian yang menyatakan bahwa kekuatan perlekatan tarik bahan bonding pada enamel yang mendapatkan perlakuan Fluor lebih rendah daripada enamel tanpa perlakuan Fluor. Teknik etsa asam dengan aplikasi asam fosfat $37 \%$ digunakan untuk memperoleh ikatan mekanik antara bahan restorasi resin komposit dan struktur gigi. Asam fosfat $37 \%$ yang diaplikasikan ini akan melarutkan sebagian hidroksi apatit dan menghasilkan pori- pori kecil pada permukaan enamel. Enamel yang ter-etsa memiliki energi permukaan yang tinggi dan memungkinkan resin untuk menembus sampai ke dalam mikroporous. Kedalaman mikroporous enamel pada umumnya setelah dilakukan etsa asam adalah sekitar 10-20 $\mu \mathrm{m}$ (Annusavice, 2004).

Pada enamel yang mendapatkan perlakuan Fluor didapatkan enamel yang lebih tahan terhadap etsa asam dimana kelarutan asam hanya mampu menembus 0,5 $-10 \mu \mathrm{m}$ porositas enamel. Hal ini dimungkinkan karena enamel gigi yang mendapatkan perlakuan Fluor membentuk ikatan kimia berupa Kalsiumfluoride dan Kalsiumphosfat. Kekerasan tulang dan gigi disebabkan oleh kadar senyawa kalsiumfosfat yang tinggi dan diantara kalsiumfosfat, hidroksiapatit merupakan senyawa yang memegang peranan paling penting (Eakle et al., 2004). Mineral enamel tersusun dari kristal apatit yang terdiri dari ion kalsium $\left(\mathrm{Ca}^{2+}\right)$, fosfat $\left(\mathrm{PO}_{4}{ }^{3-}\right)$, dan hidroksiapatit atau $\mathrm{Ca} 10\left(\mathrm{PO}_{4}\right)_{6}(\mathrm{OH})_{2}$. Setiap gugus ion dapat disubstitusi oleh ion lain, dan bila ion Fluor (F-) menggantikan gugus (OH-) akan akan membentuk Fluoroapatite atau $\mathrm{Ca}\left(\mathrm{PO}_{4}\right)_{6} \mathrm{~F}_{2}$. Fluor dapat dijumpai pada jaringan keras karena afinitasnya yang besar terhadap jaringan tulang dan mineral gigi (Eakle et al., 2004).

Enamel gigi dengan jumlah Fluoroapatit yang lebih besar akan memiliki kekerasan enamel yang lebih tinggi dan lebih tahan terhadap kondisi asam, hal ini disebabkan oleh ion Fluor yang bersifat reaktif dan memiliki afinitas yang tinggi terhadap mineral enamel dan membentuk ikatan lebih kuat dan lebih stabil terhadap kondisi asam. pemberian topikal fluoride pada gigi mampu meningkatkan kekerasan enamel (enamel microhardness) daripada gigi yang tidak dilakukan terapi fluoride (Baraa \& Aisha, 2014). Hal ini dikarenakan semakin besar remineralisasi makin besar jumlah mineral-mineral penyusun gigi sehingga meningkatkan kekerasan gigi (Featherstone, 1983).

Gigi dengan konsentrasi Fluor yang tinggi pada umumnya lebih tahan terhadap etsa asam dan membutuhkan waktu lebih lama untuk mengkondisikannya. Pengaruh Fluor pada enamel menyebabkan penurunan tegangan permukaan sehingga resin tidak mudah membasahi permukaan enamel serta menembus ke dalam mikroporous, hal ini menyebabkan penurunan perlekatan bonding. Gigi dengan Fluorosis dimana pada enamel gigi mempunyai kadar Fluor yang sangat tinggi menunjukkan penurunan perlekatan bonding jika dibandingkan dengan gigi yang normal. Penelitian yang dilakukan oleh Kimura et al., juga menunjukkan adanya kegagalan perlekatan bonding pada enamel gigi yang yang terpengaruh oleh varnis fluoride. Hal ini kemungkinan karena daya penetrasi bahan bonding ke dalam enamel yang kurang maksimal (Adanir, 2009 \& Kimura et al., 2004).

\section{KESIMPULAN}

Kekuatan perlekatan tarik bahan bonding pada enamel gigi yang mendapatkan perlakuan fluor lebih rendah daripada 
enamel gigi yang tidak mendapatkan perlakuan fluor.

\section{DAFTAR PUSTAKA}

1. Annusavice K.J., 2003. Phillips Buku Ajar Ilmu Bahan Kedokteran Gigi Ed.11.Alih bahasa : drg Johan A. Budiman. Jakarta : EGC. pp. $13-15,254$

2. Huraini, Prawati et al., Pengaruh pengulasan topikal fluor terhadap kekuatan tarik perlekatan tumpatan komposit pada gigi sulung. Kedokteran Gigi Universitas Airlangga, 2005.

3. Koch G. \& Poulson S., 2009.,Pediatric Dentistry - A Clinical Approach. $2^{\text {nd }}$ Ed.WilleyBlackwell. P.93.

4. Depkes R.I., 2013. Riset Kesehatan Dasar 2013. Badan Penelitian dan Pengembangan Kesehatan. Jakarta

5. Koch G. \& Poulson S., 2009.,Pediatric Dentistry - A Clinical Approach. $2^{\text {nd }}$ Ed.WilleyBlackwell. P.93

6. Mc Intyre J.M., 2004. Dental Caries - The Major Cause of Tooth Damage. In ; Mount GJ, Hume WR(ed). Preservation and Restoration of Tooth Structure. Queensland: Knowledge Book and Software. P. 21-45

7. Sandra Guzmán-Armstrong, D.D.S., M.S.; John J. Warren, D.D.S., M.S. Management of
High Caries Risk and High CariesActivityPatients: Rampant Caries Control Program (RCCP).Journal o dental education june 2007.

8. T. Akca, A.R. Yazici :The effect of desentizingtratments on the bond strength of resin composite to dentin mediated by a self etching primer. Operative dentistry, 2007, 32-5, 451

9. Zimmer S., Robke F.J., Roulet J.F., prevention with fluoride varnish in socially deprived community. Community Dent Oral Epidemiol 1999; 27(2):103-8.

10. Vijayaraghavan T.V., Seung-II Eom : Performance probabilitymaterial, operator and technique contribution: esthetic crown and bridge materials. J Dent rest.1998;68(12):p.1791

11. Edhie Arif P and Sri Kunarti, The effect of acidulated phosphat fluoride aplication on dental enamel surface hardness, Departement of Conservative Dentristy Faculty of Dentristry Airlangga University, Surabaya

12. Indonesia Media Dental Journal (Majalah Kedokteran Gigi) Volume : 40- No. 3 - 2007-07-01

13. Baara., Aisha "Enamel acid etching ,2014, A riview, January 28(1):662-669

14. Featherstone, 1983, Dental Material and Selection. 3rd Chicago: Quintenssence Pub CoInc.2002:44-7 